\title{
METHOD DEVELOPMENT AND VALIDATION OF ULTRAVIOLET-VISIBLE SPECTROSCOPIC METHOD FOR THE ESTIMATION OF HEPATITIS-C DRUGS - DACLATASVIR AND SOFOSBUVIR IN ACTIVE PHARMACEUTICAL INGREDIENT FORM
}

\author{
ASHOK CHAKRAVARTHY V ${ }^{1 *}$, SAILAJA BBV ${ }^{1}$, PRAVEEN KUMAR A ${ }^{2}$ \\ ${ }^{1}$ Department of Inorganic and Analytical Chemistry, Andhra University, Vishakhapatnam - 530003, Andhra Pradesh, India. ${ }^{2}$ Department of \\ Chemistry, Changwon National University, Changwon 641773, Korea. Email: mykingsenglish@gmail.com
}

Received: 10 August 2016, Revised and Accepted: 16 August 2016

\section{ABSTRACT}

Objective: The objective of the present work is to develop a simple, efficient, and reproducible spectrophotometric method for the quantitative estimation of hepatitis-C drugs - Daclatasvir and Sofosbuvir in its active pharmaceutical ingredient (API) form.

Methods: The developed ultraviolet spectrophotometric method for the quantitative estimation of hepatitis-C drugs - Daclatasvir and Sofosbuvir is based on measurement of absorption at a wavelength maximum $\left(\lambda_{\max }\right)$ of 317 and $261 \mathrm{~nm}$ using methanol as solvent.

Results: The method was validated in terms of specificity, precision, linearity, accuracy, and robustness as per the ICH guidelines. The method was found to be linear in the range of $50-150 \%$ for Daclatasvir and in the range of $43-143 \%$ for Sofosbuvir. The percentage recovery values were in the range of 99.4-100.6\% for Daclatasvir and in the range of 99.7-100.6\% for Sofosbuvir at different concentration levels. Relative standard deviation for precision and intermediate precision results were found to be $<2 \%$. The correlation coefficient value observed for Daclatasvir and Sofosbuvir drug substances was not $<0.99,0.99$, respectively. Results obtained from the validation experiments prove that the developed method is quantified for the estimation of Daclatasvir and Sofosbuvir drug substances.

Conclusion: The developed method can be successfully applied for routine analysis, quality control analysis, and also suitable for stability analysis of Daclatasvir and Sofosbuvir in API form as per the regulatory requirements.

Keywords: Daclatasvir, Sofosbuvir, Method development, Validation, Ultraviolet-visible spectrophotometry.

(C) 2016 The Authors. Published by Innovare Academic Sciences Pvt Ltd. This is an open access article under the CC BY license (http://creativecommons. org/licenses/by/4. 0/) DOI: http://dx.doi.org/10.22159/ajpcr.2016.v9s3.14616

\section{INTRODUCTION}

The chemical name of daclatasvir dihydrochloride is methyl((1S)1-(( (2S)-2-(5- (4'- (2- ( (2S)-1- ( (2S)-2- ( (methoxycarbonyl)amino)-3methylbutanoyl)-2-pyrrolidinyl)-1H-imidazol-5-yl)-4-biphenylyl)-1Himidazol-2-yl)-1-pyrrolidinyl)carbonyl)-2-methylpropyl) carbamate dihydrochloride, and this drug is used for the treatment of hepatitis- $\mathrm{C}$ virus (HCV) infection [1,2]. Daclatasvir is a chiral molecule with four stereocenters $(1,1,2,2)$ in the $\mathrm{S}$ configuration. Daclatasvir is a white to yellow crystalline non-hygroscopic powder. It is freely soluble in water, dimethyl sulfoxide, and methanol; soluble in ethanol (95\%); practically insoluble in dichloromethane, tetrahydrofuran, acetonitrile, acetone, and ethyl acetate [2]. Daclatasvir structure is shown in Fig. 1.

Daclatasvir is a first in class direct acting antiviral agent which binds to and inhibits the function of the HCV protein NS5A. NS5A is involved in both viral RNA replication and virus particle assembly. A putative inhibitor-binding region spanning amino acids 21-30 of NS5A was identified [2].

The goal of antiviral therapy against HCV is to reach sustained virological response (SVR), which is traditionally defined as the absence of quantifiable virus in plasma at least 24 weeks after the end of therapy. However, most relapses occur within 4 weeks of treatment discontinuation, and a 98-99\% concordance has been shown between absence of quantifiable virus 12 weeks after therapy and SVR24. Therefore, the absence of measurable virus 12 weeks post end of treatment (SVR12) is presently accepted by European and the US regulators as the primary endpoint in clinical trials [2].

The chemical name of Sofosbuvir is Isopropyl (2S)-2-[[[(2R,3R,4R,5R)5-(2,4-dioxopyrimidin-1-yl)-4-fluoro-3-hydroxy-4-methyl- tetrahydrofuran-2-yl]methoxy-phenoxy- phosphoryl] amino] propanoate. Sofosbuvir is a nucleotide analog used in combination with other drugs for the treatment of HCV infection. It has been marketed since 2013. Compared to previous treatments, Sofosbuvir-based regimens provide a higher cure rate, fewer side effects, and a 2 - to 4 -fold reduced duration of therapy. Sofosbuvir allows most patients to be treated successfully without the use of pegylated interferon (pegIFN), an injectable drug with severe side effects that is a key component of older drug combinations for the treatment of HCV. Sofosbuvir inhibits the RNA polymerase that the HCV uses to replicate its RNA. It was discovered at Pharmasset and developed by Gilead Sciences [3]. Sofosbuvir structure is shown in Fig. 2.

In 2013, the FDA approved Sofosbuvir in combination with ribavirin (RBV) for oral dual therapy of HCV genotypes 2 and 3 and for triple therapy with injected pegIFN and RBV for treatment-naive patients with HCV genotypes 1 and 4. In 2014, a combination of Sofosbuvir with the viral NS5A inhibitor ledipasvir was approved. This latter combination provides high cure rates in people infected with genotype 1 (the most common subtype in the U.S., Japan, and much of Europe) without the use of IFN, irrespective of prior treatment failure, or the presence of cirrhosis. In September 2014, Gilead announced that it was proposing generic licensing agreements with manufacturers in 91 developing countries to produce and sell Sofosbuvir, and that it would sell a name brand version of the product in India for approximately $\$ 300$ per course of treatment. It is on the World Health Organization's List of Essential Medicines, a list of the most important medications needed in a basic health system [3].

Sofosbuvir is a white to off-white crystalline solid and is slightly soluble in water [4] with a solubility of $\geq 2 \mathrm{mg} / \mathrm{mL}$ across the $\mathrm{pH}$ range of 2-7.7 at $37^{\circ} \mathrm{C}[5]$. Water solubility of $0.824 \mathrm{mg} / \mathrm{mL}$ and pKa value of 9.3 was reported [6]. Sofosbuvir is freely soluble in ethanol [7]. 


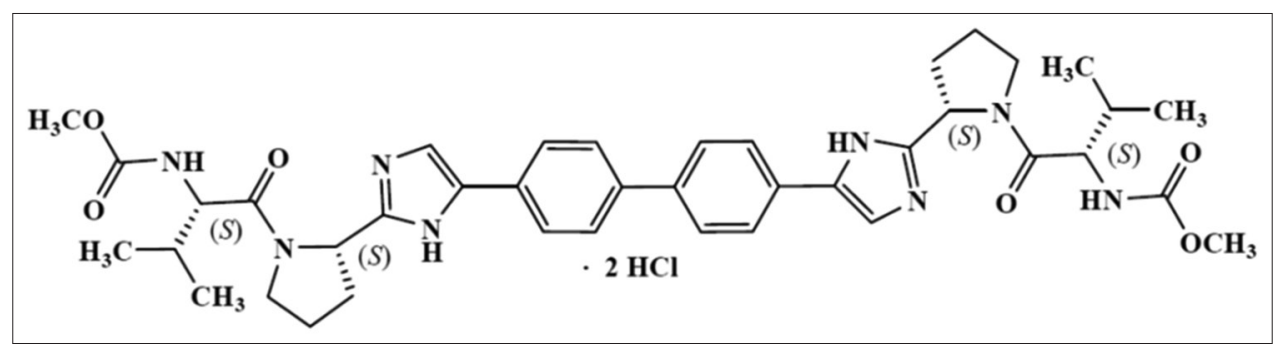

Fig. 1: Structure of Daclatasvir dihydrochloride

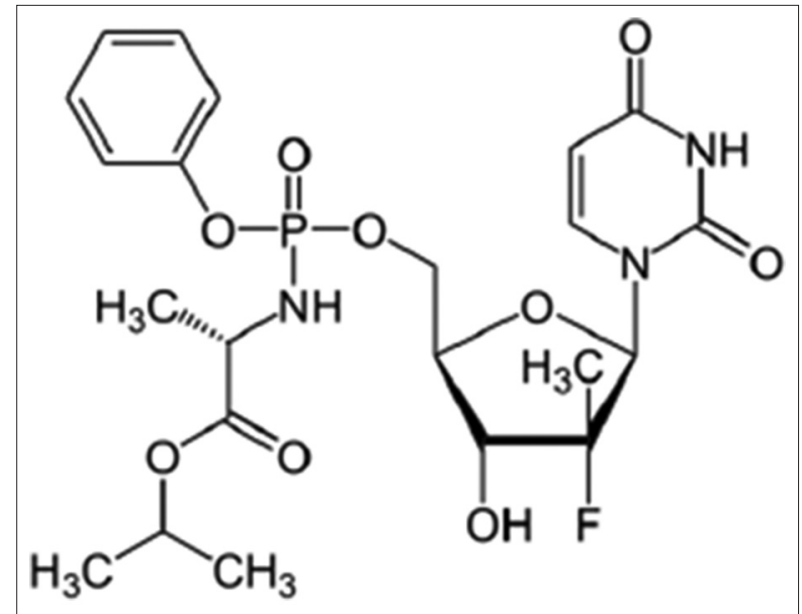

Fig. 2: Structure of Sofosbuvir

From the literature survey, it is evident that very few research articles are available for Daclatasvir and Sofosbuvir. Sundaram and Kowdley published an article on dual Daclatasvir and Sofosbuvir for the treatment of genotype 3 chronic HCV infection [8]. Bunchorntavakul and Reddy published a review article on the efficacy and safety of Daclatasvir in the treatment of chronic HCV infection [9]. Ashok and Sailaja published an article on method development and validation of assay and dissolution methods for the estimation of Daclatasvir in tablet dosage forms by reverse phase high-performance liquid chromatography (HPLC) [10] Shi et al. published an article on evaluation of a rapid method for the simultaneous quantification of RBV, Sofosbuvir, and its metabolite in rat plasma by ultra-performance liquid chromatography tandem mass spectrometry (UPLC-MS/MS) [11]. Debasish et al. published an article on the characterization of forced degradation products and in silico toxicity prediction of Sofosbuvir: A novel HCV NS5B polymerase inhibitor [12]. Pan et al. published an article on the simultaneous determination of Ledipasvir, Sofosbuvir, and its metabolite in rat plasma by UPLC-MS/MS and its application to a pharmacokinetic study [13]. Rezk et al. published an article on the development of a sensitive UPLC-ESI-MS/MS method for quantification of Sofosbuvir and its metabolite, GS-331007, in human plasma: Application to a bioequivalence study [14].

Analytical methods are not available in USP [15] and European Pharmacopoeia [16] for the quantitative determination of Daclatasvir and Sofosbuvir drugs. The present research work describes the estimation of assay content of Daclatasvir and Sofosbuvir in active pharmaceutical ingredient (API) form using ultraviolet-visible (UV-vis) spectrophotometry technique. The work gives a sensitive, specific, and economical method for the determination of Daclatasvir and Sofosbuvir in very short time by the UV-vis spectrophotometer. Methanol is used as a solvent for diluent preparation based on the drug solubility properties of both Daclatasvir and Sofosbuvir. Developed UV-vis spectrophotometric method was validated with respect to specificity, linearity, precision, accuracy, and robustness.

\section{EXPERIMENTAL}

\section{Materials and Methods}

Qualified standards (Daclatasvir purity 99.3\%, Sofosbuvir 99.9) and samples are obtained from Natco Pharma Limited and Hetero Drugs Limited and were used without any further purification. HPLC grade methanol (MeOH purity 99.8\%) was obtained from Rankem (Mumbai, India).

\section{Instrumentation}

A double beam UV-vis spectrophotometer (Shimadzu, model 1800) having two matched quartz cells with $1 \mathrm{~cm}$ light path length and loaded with UV probe software was used for recording of spectra and measuring absorbance for method development and validation study.

\section{Method development}

Selection of diluent

Methanol was used as diluent for the preparation of standards and samples for Daclatasvir and Sofosbuvir API's based on the solubility characteristics of both the drug substances.

\section{Selection of suitable wavelength detection}

Spectra for Daclatasvir and Sofosbuvir were measured from 200 to $800 \mathrm{~nm}$ for wavelength maxima by recording UV-vis spectrum of standard solution. The corresponding spectrum of Daclatasvir and Sofosbuvir is shown in Figs. 3 and 4. Maximum absorbance $\left(\lambda_{\max }\right)$ was shown at 317 and $261 \mathrm{~nm}$ for standard solution of Daclatasvir and Sofosbuvir. Based on the spectra maxima, 317 and $261 \mathrm{~nm}$ were selected for identification and quantification of Daclatasvir and Sofosbuvir drugs.

\section{Preparation of standard and sample solutions for Daclatasvir} Standard stock solution of Daclatasvir

Accurately weighed and transferred $50 \mathrm{mg}$ of Daclatasvir working standard into a $50 \mathrm{ml}$ volumetric flask. Added about $30 \mathrm{ml}$ of diluent and sonicated to dissolve with intermittent shaking. The resulting solution is diluted up to the mark with diluent and mixed well.

\section{Preparation of standard solution}

Transferred $0.4 \mathrm{ml}$ of Daclatasvir standard stock solution into a $50 \mathrm{ml}$ volumetric flask and diluted up to the mark with the diluent and mixed well.

\section{Preparation of sample solution}

Accurately weighed and transferred $50 \mathrm{mg}$ of Daclatasvir drug substance into a $50 \mathrm{ml}$ volumetric flask. Added about $30 \mathrm{ml}$ of diluent and sonicated to dissolve with intermittent shaking. The resulting solution is diluted up to the mark with diluent and mixed well. Further, diluted $0.4 \mathrm{ml}$ of Daclatasvir sample stock solution into a $50 \mathrm{ml}$ volumetric flask and diluted up to the mark with the diluent and mixed well and transferred the resultant sample solution into UV cuvettes for analysis.

Preparation of standard and sample solutions for Sofosbuvir Standard stock solution of Sofosbuvir

Accurately weighed and transferred $50 \mathrm{mg}$ of Sofosbuvir working standard into a $50 \mathrm{ml}$ volumetric flask. Added about $30 \mathrm{ml}$ of diluent 


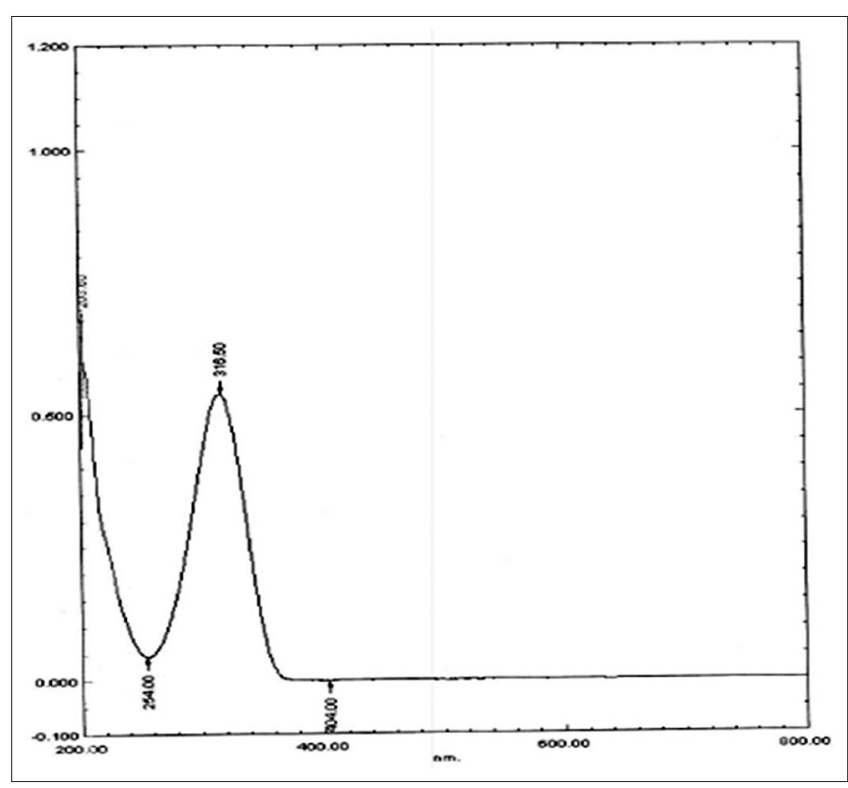

Fig. 3: Daclatasvir standard spectrum

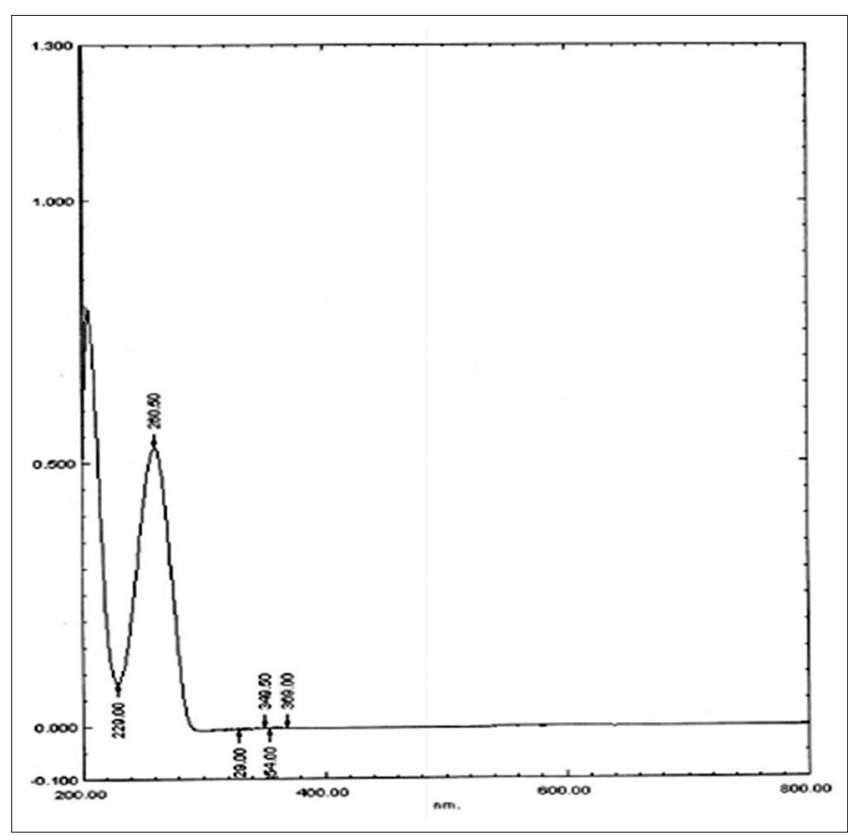

Fig. 4: Sofosbuvir standard spectrum

and sonicated to dissolve with intermittent shaking. The resulting solution is diluted up to the mark with diluent and mixed well.

\section{Preparation of standard solution}

Transferred $0.7 \mathrm{ml}$ of Sofosbuvir standard stock solution into a $25 \mathrm{ml}$ volumetric flask and diluted up to the mark with the diluent and mixed well.

\section{Preparation of sample solution}

Accurately weighed and transferred $50 \mathrm{mg}$ of Sofosbuvir drug substance into a $50 \mathrm{ml}$ volumetric flask. Added about $30 \mathrm{ml}$ of diluent and sonicated to dissolve with intermittent shaking. The resulting solution is diluted up to the mark with diluent and mixed well. Further, diluted $0.7 \mathrm{ml}$ of Sofosbuvir sample stock solution into a $25 \mathrm{ml}$ volumetric flask and diluted up to the mark with the diluent and mixed well and transferred the resultant sample solution into UV cuvettes for analysis.

\section{Method validation Specificity/stress studies}

Specificity is the ability to assess unequivocally the analyte in the presence of components which may be expected to be present. Typically these might include impurities, degradants, and matrix [17]. The specificity of the developed method was established to prove the absence of interference from diluent absorbance which is part of required pharmaceutical drug substance preparation.

\section{Linearity}

Linearity is the ability of the method to obtain results which are either directly or after mathematical transformation proportional to the concentration of the analyte within a given range. The linearity of response for Daclatasvir and Sofosbuvir was determined in the range from $50 \%$ to $150 \%$ for Daclatasvir and in the range of $43-143 \%$ for Sofosbuvir. The five concentrations of each component were subjected to regression analysis by least squares method to calculate correlation coefficient and calibration equation. The method of linear regression was used for the data evaluation.

\section{Precision}

Precision is a measure of the reproducibility of the whole analytical method under normal operating conditions. The precision was expressed as the relative standard deviation (RSD).

$\% \mathrm{RSD}=($ Standard deviation/average $) \times 100$

The precision of the developed method was carried out by six determinations (preparations) of the test solution by measuring the absorbance of test solution and calculated the \% RSD for estimation of drug content.

\section{Accuracy}

Accuracy or trueness was determined by applying the method to samples, in which known amounts of analyte have been added. These should be analyzed against standard and blank solutions to ensure that no interference exists. The accuracy was calculated from the test results as a percentage of the analyte recovered by the assay.

The accuracy of the present method was carried out using the drug substance spiked solution at three different concentration levels of $50 \%$, $100 \%$, and $150 \%$ for Daclatasvir and $43 \%, 100 \%$, and $143 \%$ for Sofosbuvir, in triplicate determinations. Percent recovery and the mean percentage recovery were calculated for Daclatasvir and Sofosbuvir drug substances.

\section{Robustness}

Robustness of the method indicates the reliability of analysis to assess the system suitability parameters under the influence of small but deliberate variations in method parameters. Robustness was performed by changing the detection wavelength $\pm 2 \mathrm{~nm}$ to the wavelength maximum $\left(\lambda_{\max }\right)$ and calculating the $\%$ assay and $\%$ RSD for the test solution.

\section{Solution stability}

Daclatasvir and Sofosbuvir sample solutions and the standard solutions were prepared as per the test procedure. All these solutions were divided into two portions. One portion was stored at room temperature, and the other portion was stored in the refrigerator at $2-8^{\circ} \mathrm{C}$. Freshly prepared solutions and the solutions, which were stored at room temperature and in refrigerator $\left(2-8^{\circ} \mathrm{C}\right)$ up to $24 \mathrm{hrs}$, were measured for absorbance at different time intervals. The $\%$ assay obtained at initial was compared with the $\%$ assay obtained at different time intervals.

\section{RESULTS AND DISCUSSION}

Optimization of UV-vis spectrophotometric method conditions The main purpose of the current method is to develop a simple, sensitive, and precise UV-vis spectrophotometric method for the estimation of 
Daclatasvir and Sofosbuvir for the routine quantitative determination of samples which will reduce tedious sample preparations, cost of materials and manpower required to perform the analysis. Daclatasvir and Sofosbuvir are UV-absorbing molecules with specific chromophores in the structure that absorb at a particular wavelength, and this absorbance was successfully employed for their quantitative determinations using the UV spectroscopic method. The spectral analysis showed that the $\lambda_{\text {m }}$ of Daclatasvir and Sofosbuvir are 317 and $261 \mathrm{~nm}$, respectively. Simple diluent methanol was selected for the standard and sample solutions of Daclatasvir and Sofosbuvir drug substances. Thus, the developed UV-vis spectroscopic method for the analysis of Daclatasvir and Sofosbuvir in its API form enables analysis of several samples at the same time due to its simplicity in performing the analysis.

The UV-vis spectra of blank run, Daclatasvir standard solution (concentration - $8 \mu \mathrm{g} / \mathrm{mL}$ ), Daclatasvir sample solution (concentration $8 \mu \mathrm{g} / \mathrm{mL}$ ), Sofosbuvir standard solution (concentration - $28 \mu \mathrm{g} / \mathrm{mL}$ ) and Sofosbuvir sample solution (concentration - $28 \mu \mathrm{g} / \mathrm{mL}$ ) are shown in Figs. 3-7.

\section{Method validation}

The objective of validation of an analytical procedure is to demonstrate that it is suitable for its intended use. The described UV-vis spectrophotometric method for the estimation of Daclatasvir and Sofosbuvir has been

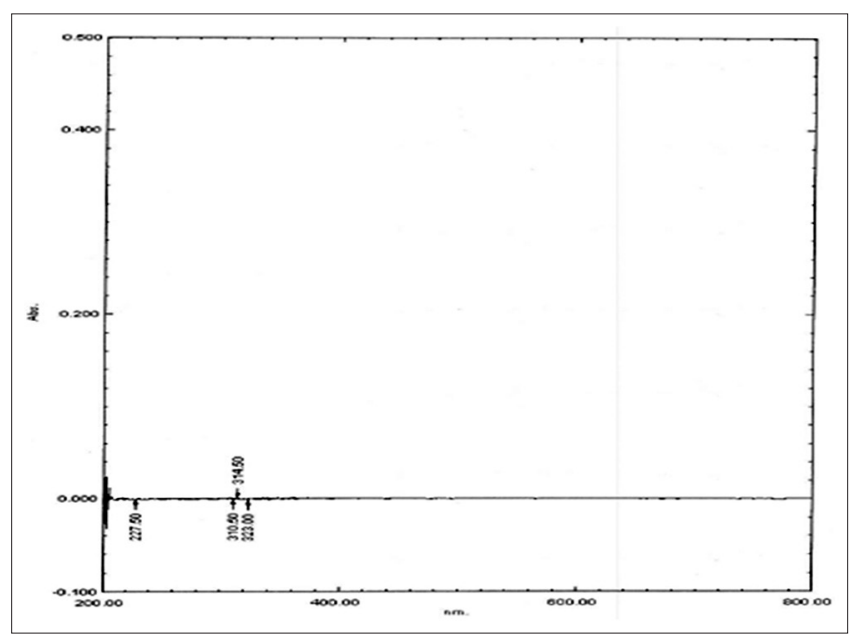

Fig. 5: Blank spectrum

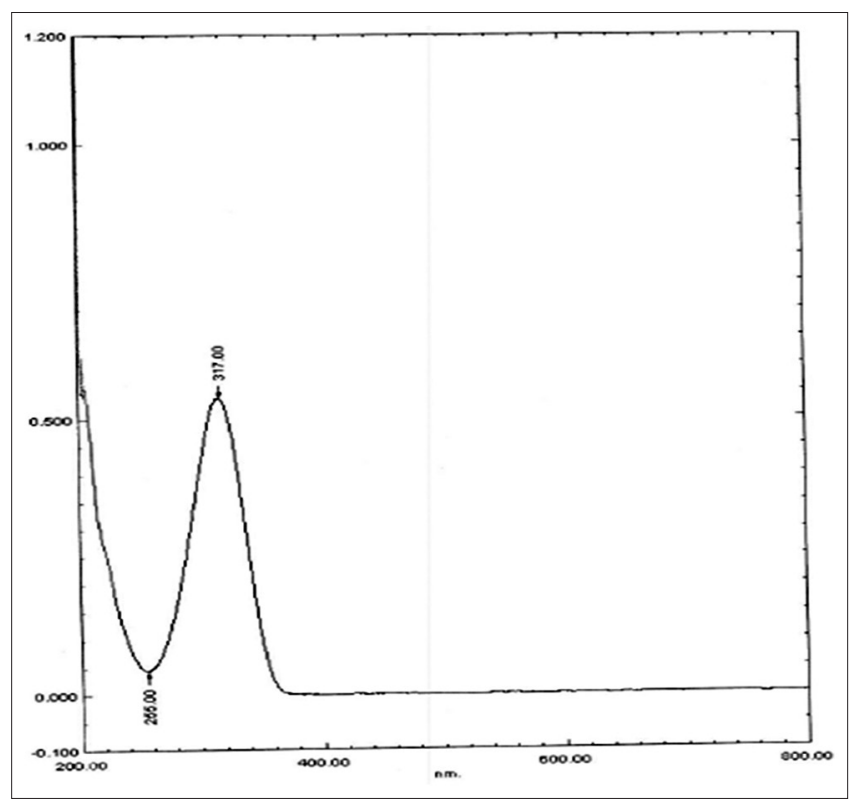

Fig. 6: Daclatasvir sample spectrum extensively validated for identification and quantification of its drug substances as per ICH guidelines [17]. After successful completion of method development $[10,18]$, method validation [17,19-21] was performed to ensure that the developed method was capable of giving reproducible and reliable results when used by different operators employed on the same equipment of the same laboratory or different laboratories. The developed UV-vis spectrophotometric method was validated to quantify Daclatasvir and Sofosbuvir in its API form by determining the parameters including specificity, precision, linearity, accuracy, and robustness according to the ICH guidelines.

\section{Specificity}

Specificity of the developed method was performed by scanning the UVvis spectra of diluent, standard, and sample solutions of Daclatasvir and Sofosbuvir from 200 to $800 \mathrm{~nm}$. Furthermore, spectral homogeneity of Daclatasvir and Sofosbuvir control samples found to be similar with those obtained for the standard solutions of Daclatasvir and Sofosbuvir

\section{Precision}

Method precision was determined by analyzing the test solution of six determinations, and the observed values of \% RSD were shown in Table 1. \% RSD for Daclatasvir and Sofosbuvir compounds in test

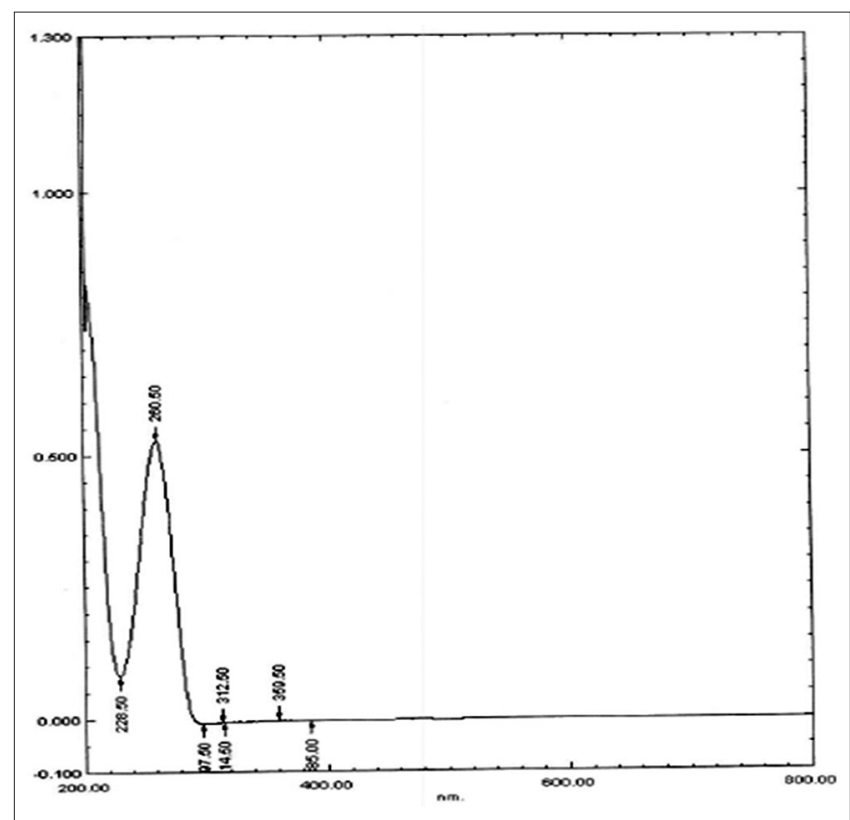

Fig. 7: Sofosbuvir sample spectrum

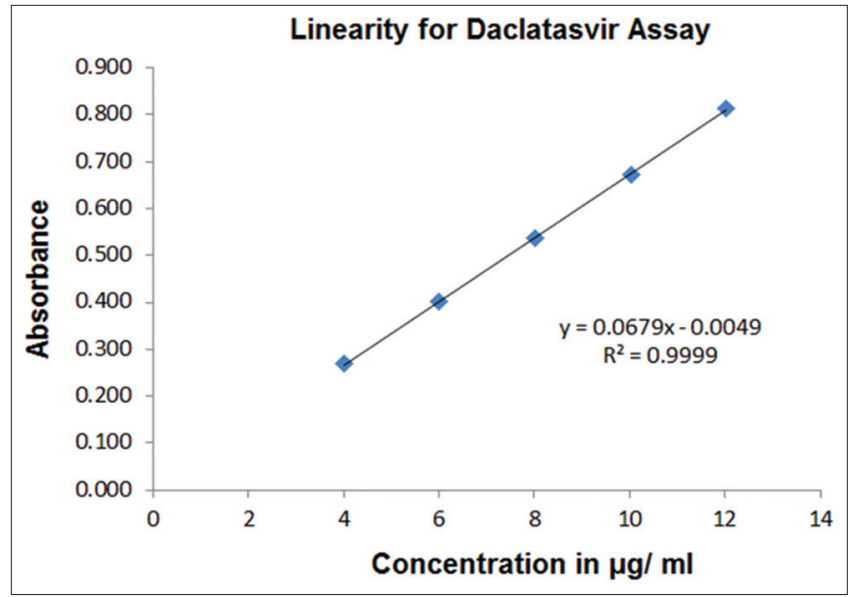

Fig. 8: Linearity graph of Daclatasvir 
Table 1: Precision and intermediate precision data

\begin{tabular}{|c|c|c|c|c|}
\hline \multirow[t]{3}{*}{ Determination } & \multicolumn{4}{|l|}{ (\% Assay) } \\
\hline & \multicolumn{2}{|l|}{ For Daclatasvir } & \multicolumn{2}{|l|}{ For Sofosbuvir } \\
\hline & Method precision & Intermediate precision & Method precision & Intermediate precision \\
\hline Determination-1 & 100.2 & 99.5 & 100.1 & 100.0 \\
\hline Determination-2 & 99.7 & 99.6 & 99.9 & 100.4 \\
\hline Determination-3 & 99.5 & 99.7 & 100.0 & 99.7 \\
\hline Determination-4 & 99.4 & 99.3 & 100.2 & 99.8 \\
\hline Determination-6 & 99.3 & 99.7 & 100.0 & 99.8 \\
\hline Average & 99.6 & 99.6 & 100.0 & 99.9 \\
\hline SD & 0.32 & 0.17 & 0.17 & 0.26 \\
\hline$\%$ RSD & 0.32 & 0.17 & 0.17 & 0.26 \\
\hline
\end{tabular}

SD: Standard deviation, RSD: Relative standard deviation

solution for six determinations was not more than $2.0 \%$. Intermediate precision of the method was studied by analyzing the test solution of six determinations, and the observed results were shown in Table 1. The $\%$ RSD difference between the two analysts is $0.15 \%$ and $0.09 \%$ for Daclatasvir and Sofosbuvir, respectively. Less difference between the two analysts shows that the developed method is precise and has good intermediate precision.

\section{Linearity}

The linearity graphs were plotted between the absorbance versus concentration to obtain the calibration curve. Linearity graphs for Daclatasvir and Sofosbuvir were shown in Figs. 8 and 9. The response obtained for Daclatasvir and Sofosbuvir was found to be linear from $50 \%$ to $150 \%$ and $43 \%$ to $143 \%$ of standard concentration. The correlation coefficient observed for Daclatasvir and Sofosbuvir compounds was not $<0.99$ and also statistical values of all compounds were shown in Table 2. Results demonstrate that an excellent correlation between the absorbance and concentration of Daclatasvir and Sofosbuvir drug substances.

\section{Accuracy}

The percentage recovery results for Daclatasvir and Sofosbuvir were varied from $99.4 \%$ to $100.6 \%$ and $99.7 \%$ to $100.6 \%$ at three different concentration levels, and the results were shown in Table 3 . Based on the $\%$ recovery data, it was concluded that the developed method is capable for the estimation of Daclatasvir and Sofosbuvir drug substances and is adequate for routine analysis.

\section{Robustness}

The robustness of the proposed method was performed by preparing the standard solutions and test solutions of Daclatasvir and Sofosbuvir at $100 \%$ level were analyzed by a change in wavelength for absorbance readings. The wavelength selected was $\pm 2 \mathrm{~nm}$ to the $\lambda_{\max }$ i.e., 315 and $319 \mathrm{~nm}$ for Daclatasvir drug and 259 and $263 \mathrm{~nm}$ for Sofosbuvir drug, respectively, for standard and sample solutions. In the robustness condition (wavelength variation of $\pm 2 \mathrm{~nm}$ to the $\lambda_{\max }$ ), the assay values of Daclatasvir and Sofosbuvir were not $<99 \%$. \% Assay results for robustness parameters were shown in Table 4.

\section{Solution stability}

The percent assay value difference was determined for solutions stored at room temperature and at refrigerated condition $\left(2-8^{\circ} \mathrm{C}\right)$ for different time intervals up to $24 \mathrm{hrs}$. Daclatasvir and Sofosbuvir absorbances were found to be stable up to $24 \mathrm{hrs}$ at room temperature and also at refrigerator condition. Solution stability results at room temperature and refrigerated condition were shown in Table 5.

\section{CONCLUSIONS}

Simple, precise, and economical UV-vis spectrophotometric method has been developed for the quantitative estimation of Daclatasvir and
Table 2: Optical characteristics and linearity data

\begin{tabular}{lll}
\hline Parameter & Daclatasvir & Sofosbuvir \\
\hline $\begin{array}{l}\text { Detection } \\
\text { wavelength }\left(\lambda_{\max }\right)\end{array}$ & $317 \mathrm{~nm}$ & $261 \mathrm{~nm}$ \\
$\begin{array}{l}\text { Beer's law limits } \\
(\mu \mathrm{m} / \mathrm{ml})\end{array}$ & $4-12(\mu \mathrm{g} / \mathrm{ml})$ & $12-40(\mu \mathrm{g} / \mathrm{ml})$ \\
$\begin{array}{l}\text { Regression statistics } \\
\text { Slope }\end{array}$ & & \\
$\begin{array}{l}\text { Intercept } \\
\text { Correlation }\end{array}$ & 0.0679 & 0.0190 \\
$\begin{array}{l}\text { coefficient } \\
\text { Coefficient of }\end{array}$ & 0.0049 & 0.0068 \\
determination $\left(\mathrm{R}^{2}\right)$ & 0.9999 & 0.9992 \\
$\begin{array}{l}\text { Intercept at } 95 \% \\
\text { confidence interval } \\
\text { (lower value-upper }\end{array}$ & $0.01692-0.00705$ & 0.9984 \\
$\begin{array}{l}\text { value) } \\
\text { Slope at 95\% } \\
\text { confidence interval } \\
\text { (lower value-upper }\end{array}$ & & \\
value) & & \\
\hline
\end{tabular}

Table 3: Accuracy results

\begin{tabular}{llll}
\hline $\begin{array}{l}\text { \% Accuracy } \\
\text { level for } \\
\text { Daclatasvir }\end{array}$ & $\begin{array}{l}\text { \% Recovery } \\
\text { range for } \\
\text { triplicate } \\
\text { preparations }\end{array}$ & $\begin{array}{l}\text { \% Accuracy } \\
\text { level for } \\
\text { Sofosbuvir }\end{array}$ & $\begin{array}{l}\text { \% Recovery } \\
\text { range for } \\
\text { triplicate } \\
\text { preparations }\end{array}$ \\
\cline { 2 - 2 } \cline { 4 - 4 } & Daclatasvir & & Sofosbuvir \\
\hline 50 & $99.6-100.3$ & 43 & $99.7-100.6$ \\
100 & $99.4-99.8$ & 100 & $99.8-100.2$ \\
150 & $99.9-100.6$ & 143 & $99.7-99.9$ \\
\hline
\end{tabular}

Table 4: Robustness results

\begin{tabular}{lllll}
\hline Determination & $\begin{array}{l}\text { \% Assay of } \\
\text { Daclatasvir } \\
\text { at } \mathbf{3 1 5} \mathbf{~ n m}\end{array}$ & $\begin{array}{l}\text { \%aclatasvir } \\
\text { at 319 } \mathbf{~ n m}\end{array}$ & $\begin{array}{l}\text { \%ofosbuvir } \\
\text { at 259 } \mathbf{~ n m}\end{array}$ & $\begin{array}{l}\text { Sofosbuvir } \\
\text { at 263 } \mathbf{~ n m}\end{array}$ \\
\hline Determination-1 & 99.5 & 99.5 & 99.9 & 99.9 \\
Determination-2 & 99.3 & 99.3 & 99.9 & 100.1 \\
Determination-3 & 99.4 & 99.4 & 100.0 & 99.9 \\
Average & 99.4 & 99.4 & 100.0 & 100.0 \\
SD & 0.11 & 0.11 & 0.08 & 0.12 \\
\%RSD & 0.11 & 0.12 & 0.08 & 0.12 \\
\hline
\end{tabular}

SD: Standard deviation, RSD: Relative standard deviation

Sofosbuvir in its API form. Method is validated as per the ICH guidelines and also the developed method is robust with respect to wavelength 
Table 5: Solution stability results of standard and control sample at room temperature and at refrigerated condition

\begin{tabular}{|c|c|c|c|c|c|}
\hline \multirow[t]{2}{*}{ Solution stability } & \multicolumn{5}{|c|}{$\%$ Assay results } \\
\hline & Initial & $\begin{array}{l}\text { After } \\
6 \mathrm{hrs}\end{array}$ & $\begin{array}{l}\text { After } \\
12 \mathrm{hrs}\end{array}$ & $\begin{array}{l}\text { After } \\
24 \text { hrs }\end{array}$ & \% Difference \\
\hline \multicolumn{6}{|l|}{ Daclatasvir solution stability } \\
\hline$\%$ Assay of standard solution at RT & 99.9 & 99.7 & 99.7 & 99.5 & 0.4 \\
\hline \% Assay of sample solution at RT & 100.2 & 100.0 & 99.8 & 99.7 & 0.5 \\
\hline$\%$ Assay of standard solution at $2-8^{\circ} \mathrm{C}$ & 99.9 & 99.9 & 99.5 & 99.3 & 0.6 \\
\hline$\%$ Assay of sample solution at $2-8^{\circ} \mathrm{C}$ & 100.2 & 99.8 & 99.7 & 99.5 & 0.7 \\
\hline \multicolumn{6}{|l|}{ Sofosbuvir solution stability } \\
\hline$\%$ Assay of standard solution at RT & 100.0 & 99.8 & 99.6 & 99.6 & 0.4 \\
\hline \% Assay of sample solution at RT & 100.1 & 100.1 & 99.9 & 99.7 & 0.4 \\
\hline$\%$ Assay of standard solution at $2-8^{\circ} \mathrm{C}$ & 100.0 & 99.8 & 99.6 & 99.8 & 0.4 \\
\hline$\%$ Assay of sample solution at $2-8^{\circ} \mathrm{C}$ & 100.1 & 99.9 & 99.7 & 99.5 & 0.6 \\
\hline
\end{tabular}

RT: Room temperature

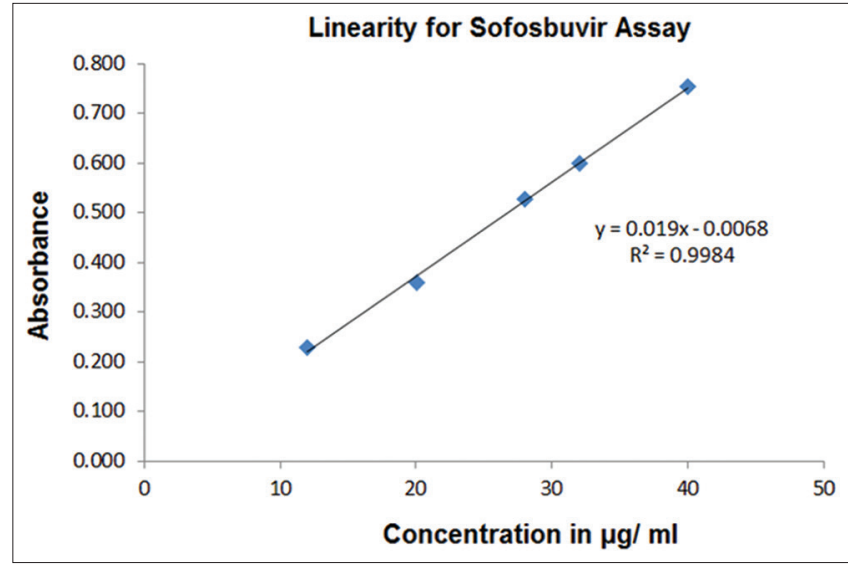

Fig. 9: Linearity graph of Sofosbuvir

variation to the original wavelength. The developed method can be used for the quantification of Daclatasvir and Sofosbuvir drug substances in routine analysis.

\section{ACKNOWLEDGMENTS}

The authors would like to thank the Department of Inorganic and Analytical Chemistry, Andhra University, Vishakhapatnam, Andhra Pradesh, India, for their encouragement.

\section{REFERENCES}

1. Available from: https://www.en.wikipedia.org/wiki/Daclatasvir.

2. Assessment Report of Daclatasvir from European Medicines Agency (EMA). Available from: http://www.ema.europa.eu/docs/en_GB/ document library/EPAR - Public assessment report/human/003768/ WC500172849.pdf.

3. Available from: https://www.en.wikipedia.org/wiki/Sofosbuvir.

4. Product monograph template - Standard from Gilead Sciences. Available from: https://www.google.co.in/?gws $\mathrm{rd}=\mathrm{ss} \| \mathrm{A}=$ =sofosbuvir + product + monograph.

5. Drug description in RxList. Available from: http://www.rxlist.com/ sovaldi-drug.htm.

6. Information source from drug bank on Sofosbuvir. Available from: http://www.drugbank.ca/drugs/DB08934.

7. Summary on Compassionate use for Sofosbuvir from European
Medicines Agency (EMA). Available from: http://www.ema.europa.eu/ docs/en_GB/document_library/Other/2013/12/WC500156825.pdf.

8. Sundaram V, Kowdley KV. Dual daclatasvir and sofosbuvir for treatment of genotype 3 chronic hepatitis $\mathrm{C}$ virus infection. Expert Rev Gastroenterol Hepatol 2016;10(1):13-20.

9. Bunchorntavakul C, Reddy KR. Review article: the efficacy and safety of daclatasvir in the treatment of chronic hepatitis $\mathrm{C}$ virus infection. Aliment Pharmacol Ther 2015;42(3):258-72.

10. Ashok CV, Sailaja BB. Method development and validation of assay and dissolution methods for the estimation of daclatasvir in tablet dosage forms by reverse phase HPLC. Eur J Pharm Med Res 2016;3(7):356-64.

11. Shi X, Zhu D, Lou J, Zhu B, Hu AR, Gan D. Evaluation of a rapid method for the simultaneous quantification of ribavirin, sofosbuvir and its metabolite in rat plasma by UPLC-MS/MS. J Chromatogr B Analyt Technol Biomed Life Sci 2015;1002:353-7.

12. Debasish S, Gananadhamu S, Shweta B, Bharatam PV, Venkatakrishna A, Barij NS. Characterization of forced degradation products and in silico toxicity prediction of Sofosbuvir: A novel HCV NS5B polymerase inhibitor. J Pharm Biomed Anal 2016;120:352-63.

13. Pan C, Chen Y, Chen W, Zhou G, Jin L, Zheng Y, et al. Simultaneous determination of ledipasvir, sofosbuvir and its metabolite in rat plasma by UPLC-MS/MS and its application to a pharmacokinetic study. J Chromatogr B Analyt Technol Biomed Life Sci 2016;1008:255-9

14. Rezk MR, Basalious EB, Karim IA. Development of a sensitive UPLCESI-MS/MS method for quantification of sofosbuvir and its metabolite, GS-331007, in human plasma: Application to a bioequivalence study. J Pharm Biomed Anal 2015;114:97-104

15. USP 37, NF 32. United States Pharmacopeial Convention, Rochville, Md, USA; 2014.

16. European Pharmacopoeia 8.0

17. ICH, Q2(R1). Harmonized Tripartite Guideline, Validation of Analytical Procedures: Text and Methodology in Proceedings of the International Conference on Harmonization of Technical Requirements for Registration of Pharmaceuticals for Human use; 2005.

18. Ashok CV, Sailaja BBV, Praveen KA. Development and validation of a dissolution method for Frovatriptan tablets by reverse phase UPLC. Int J Pharm Pharm Sci 2015;7(4):125-30.

19. Ravichandran V, Shalini S, Sundramand KM, Rajak H. Validation of analytical methods-strategies and importance. Int J Pharm Pharm Sci 2010;2(3):18-22.

20. United States Food and Drug Administration. Guidance for Industry: Analytical Procedures and Methods Validation: Chemistry, Manufacturing, and Controls Documentation. Rockville, MD: Draft Guidance USFDA; 2001.

21. Validation of Compendial Methods. United States Pharmacopeia 37, National Formulary 32. Ch. 1225. The United States Pharmacopeial Convention, Rockville, MD, USA; 2014. 